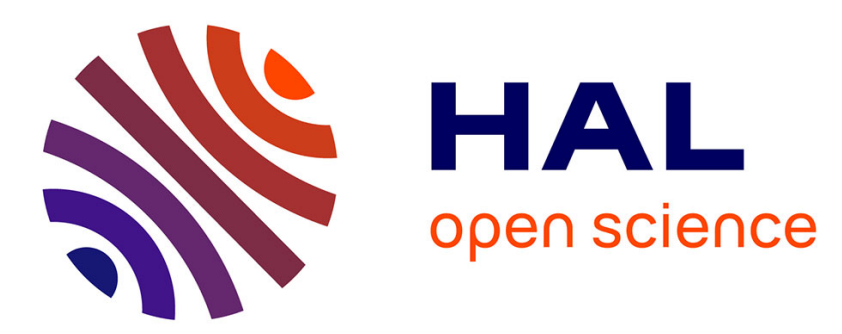

\title{
Properties of Ga1-yAlyAs 1-xSbx/GaAs1- xSbx double heterojunction electroluminescent diodes
}

\author{
J. Varon, M. C. Boissy, J. Lebailly
}

\section{To cite this version:}

J. Varon, M. C. Boissy, J. Lebailly. Properties of Ga1-yAlyAs 1-xSbx/GaAs1- xSbx double heterojunction electroluminescent diodes. Revue de Physique Appliquée, 1978, 13 (12), pp.661-666. 10.1051/rphysap:019780013012066100 . jpa-00244522

\section{HAL Id: jpa-00244522 https://hal.science/jpa-00244522}

Submitted on 1 Jan 1978

HAL is a multi-disciplinary open access archive for the deposit and dissemination of scientific research documents, whether they are published or not. The documents may come from teaching and research institutions in France or abroad, or from public or private research centers.
L'archive ouverte pluridisciplinaire HAL, est destinée au dépôt et à la diffusion de documents scientifiques de niveau recherche, publiés ou non, émanant des établissements d'enseignement et de recherche français ou étrangers, des laboratoires publics ou privés. 


\title{
DISPLAYS, PHOTOEMITTORS.
}

\section{PROPERTIES OF $\mathbf{G a}_{1-y} \mathbf{A l}_{y} \mathbf{A s}_{1-x} \mathbf{S b}_{x} / \mathbf{G a A s}_{1-x} \mathbf{S b}_{x}$ DOUBLE HETEROJUNCTION ELECTROLUMINESCENT DIODES $\left(^{*}\right)$}

\author{
J. VARON, M. C. BOISSY and J. LEBAILLY
}

R.T.C. La Radiotechnique Compelec, B.P. 6025, 14001 Caen, France

\begin{abstract}
Résumé. - L'étude des hétérostructures $\mathrm{GaAs}_{1-x} \mathrm{Sb}_{x} / \mathrm{Ga}_{1-y} \mathrm{Al}_{y} \mathrm{As}_{1-x} \mathrm{Sb}_{x}$ se justifie par le grand intérêt que présentent ces composés en particulier dans le domaine des transmissions par fibre optique. La gamme de compositions explorée dans cet article $(0 \leqslant x \leqslant 0,25)$ est à même de conduire à des dispositifs dont le domaine d'utilisation se trouve dans la bande spectrale 0,9 à $1,2 \mu \mathrm{m}$, ce qui permet de bénéficier des propriétés de faible absorption et surtout de faible dispersion des fibres.

La croissance de ces matériaux se fait par épitaxie liquide, au cours de laquelle on doit réaliser une adaptation de maille entre le substrat de GaAs et la couche active de GaAsSb. La forme optimale de cette couche tampon est une gradation par sauts dans laquelle l'écart de composition entre deux couches successives doit augmenter progressivement en partant du substrat.

La caractérisation du matériau ternaire ainsi élaboré et l'analyse des performances des dispositifs réalisés à l'aide de l'hétérostructure se rejoignent et mettent en évidence une décroissance de l'efficacité des transitions radiatives lorsque la composition en antimoine de la couche active augmente. On l'explique par la dégradation de la qụalité cristalline du matériau lorsque le désaccord de maille devient trop important pour être totalement pris en charge par la couche tampon. Ceci conduit à limiter le domaine d'utilisation du GaAsSb entre 0,9 et $1,1 \mu \mathrm{m}$, intervalle où ses bonnes performances en électroluminescence le désignent comme un matériau tout à fait adapté à cet usage.
\end{abstract}

\begin{abstract}
The need for light sources and detectors in optical communications has stimulated the evaluation of physical properties of the $\mathrm{GaAs}_{1-x} \mathrm{Sb}_{x} / \mathrm{Ga}_{1-y} \mathrm{Al}_{y} \mathrm{As}_{1-x} \mathrm{Sb}_{x}$ double heterojunction. In this paper the research is limited to the composition range $0 \leqslant x \leqslant 0.25$, which corresponds to the spectral range $0.9-1.2 \mu \mathrm{m}$, specially attractive for optical fiber communications because of the lowest absorption and dispersion losses.

In this research the metallurgical study is an important feature; during the LPE growth, lattice matching has to be performed between the GaAs substrate and the ternary active layer. This is carried out by a particular step-greading technic where the compositional steps have to be progressively increased from the bottom to the top of the buffer layer.

The results of the material characterization and of the measurements of properties of the double heterojunction devices thus performed are compatible and point out that the radiative transition efficiency decreases as the antimony content in the active layer is increased. This is ascribed to the degradation of the crystalline quality occurring when the lattice mismatch is too large to be solved by the step-grading buffer layer. So that the working range of GaAsSb is reduced to 0.9 to $1.1 \mu \mathrm{m}$ where its electroluminescence performances are quite satisfactory and justify the interest of this compound.
\end{abstract}

1. Introduction. - In the field of optical communications, the 1.0 to $1.2 \mu \mathrm{m}$ range seems very attractive. Indeed both optical losses and material dispersion in silica fibers are appreciably smaller here than in the 0.8 to $0.9 \mu \mathrm{m}$ range. These main advantages explain the interest recently devoted $[1,2,3]$ to the double heterostructure $\mathrm{GaAs}_{1-x} \mathrm{Sb}_{x} / \mathrm{Ga}_{1-y} \mathrm{Al}_{y} \mathrm{As}_{1-x} \mathrm{Sb}_{x}$ which can lead to devices, light sources as well as photodetectors, useable in fiber-optic systems operating beyond $1.0 \mu \mathrm{m}$.

For the double heterojunction light-emitting diodes made of this quaternary, the principle is as simple as for GaAs/GaAlAs : electronic and optical confinements on both sides of the active layer are due to the introduction of aluminium which does not

$\left(^{*}\right)$ This work was partly supported by the Délégation Générale à la Recherche Scientifique et Technique. induce appreciable lattice mismatch. On the contrary the lattice parameters of the GaAs substrate and of the $\mathrm{GaAs}_{1-x} \mathrm{Sb}_{x}$ active layer are quite different and this mismatch increases with the antimony molar fraction in the active layer. This fact induces the main problem of this structure and, as the physical properties of the material have direct influence on the electrical and optical characteristics of the elaborated device, attention must be firstly focused on the metallurgic point of view.

Thus this paper deals with the physical properties of the $\mathrm{GaAsSb} / \mathrm{GaAlAsSb}$ heterostructure and with its potential application to LED's.

2. Experimental : metallurgical point of view. 2.1 Crystal Growth TeChNic. - The GaAsSb layers are grown by liquid phase epitaxy from a gallium rich solution. The GaAs substrates are 
obtained from ingots grown by the gradient freeze method with silicon doping concentration ranging from $2 \times 10^{17}$ to $10^{18} \mathrm{~cm}^{-3}$ and with a dislocation density of about $10^{3}$ to $10^{4} \mathrm{~cm}^{-2}$. Substrate wafers about $500 \mu \mathrm{m}$ thick are lapped and subsequently mecano-chemically polished. Their surfaces are oriented in the (100) plane. These surfaces are then etched and cleaned just before epitaxy.

The growth is performed in an horizontal sliding boat with several compartments. The gallium solution contains GaAs for saturation and metallic antimony. The temperature choosen for the beginning of epitaxy is around $780{ }^{\circ} \mathrm{C}$; after homogeneization, the growth occurs by lowering continuously the furnace temperature with the constant rate $0.5^{\circ} \mathrm{C} / \mathrm{mn}$. With these conditions, the growth rate is about $1 \mu \mathrm{m} /{ }^{\circ} \mathrm{C}$.

2.2 Optimization OF THE LATTICE MATCHING. In a first set of experiments one single GaAsSb layer is grown directly onto the substrate. The other conditions being kept constant, different weights of antimony in the solution are tried to get ternary layers with different $\mathrm{Sb}$ compositions, from 1 to $10 \%$. The surface of these different layers is bright but shows a network of lines having the [110] directions. As shown in figure 1 , the greater the concentration of $\mathrm{Sb}$ in the ternary layer, the more pronounced this network. As the composition $x$ increases, the difference in lattice constant between the GaAs substrate and the $\mathrm{GaAs}_{1-x} \mathrm{Sb}_{x}$ layer gets greater and the growth occurs in a more disturbed way. This is the reason why a buffer layer with compositional grading is needed when the concentration of the ternary layer exceeds $8 \%$.

In this structure it is necessary to increase the lattice constant from that of the substrate (the epitaxial layer is under compression); so the step-grading technique is particularly valuable to perform the buffer layer. In this method, the misfit dislocations generated at the substrate or between the steps are bent over at the next compositional step, so that the upper active layer has a low dislocation density [4].

The influence of the characteristics of this buffer layer, such as the number of steps and the variation of composition between two steps, on the crystallographic quality is viewed for an uppermost layer containing $12 \%$ of antimony. First the number of buffer layers is fixed, equal to 4 , and the form of the compositional grading is varied. Indeed this stepgrading may occur in three different ways : the variation of composition at each step may be the same for all the four layers (configuration used by all the authors) or on the contrary this variation of composition between two successive layers can decrease, or increase, from the bottom of the buffer layer. Figure 2 shows the surface of the uppermost layer (with $12 \% \mathrm{Sb}$ ) obtained with a step-grading performed in each of these 3 ways. For compositional steps decreasing from the substrate to the upper layer (case $a$ ), the surface is greatly disturbed, evidence of a notable crystallographic disorder. When the compositional step is the same all over the buffer layer (case $b$ ), the growth seems to have occurred in a more ordered way but the network of [110] lines is well marked. At last the best result is obtained with increasing compositional steps (case $c$ ). This tends to indicate that the variation of $\mathrm{Sb}$ composition $\Delta x$ which is allowed between two successive layers depends on the composition $x$ of the first grown of these two layers. In fact the relative variation of composition $\Delta x / x$ is limited by the elasticity of the material, so that the composition step has to be progressively increased at

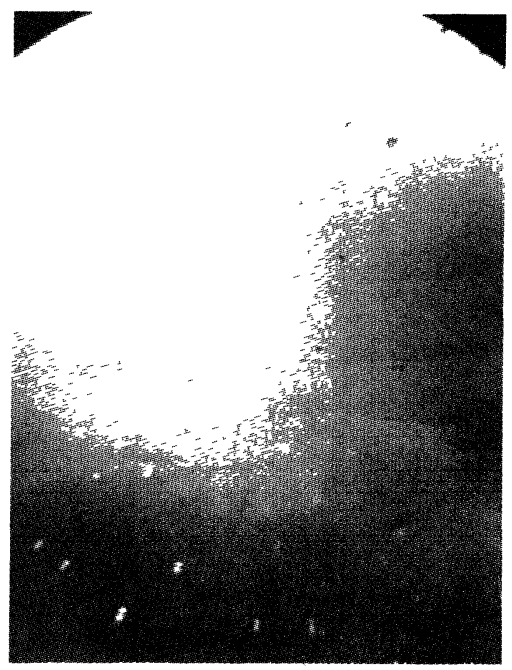

$\mathrm{x} \mathrm{Sb}=1,6 \%$

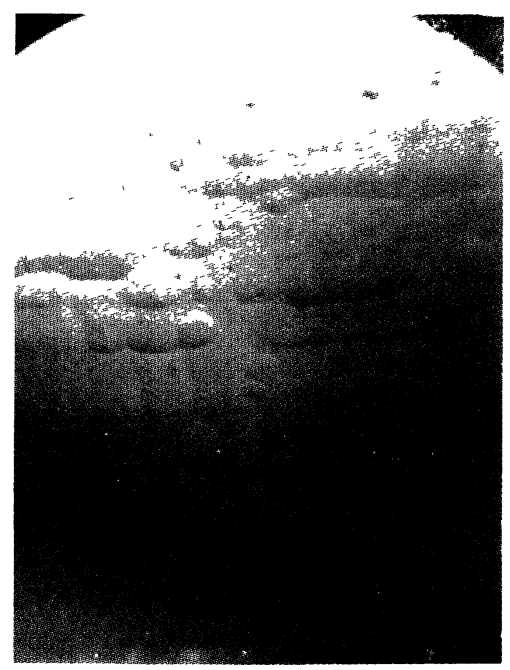

$\mathrm{x} \mathrm{Sb}=6 \%$

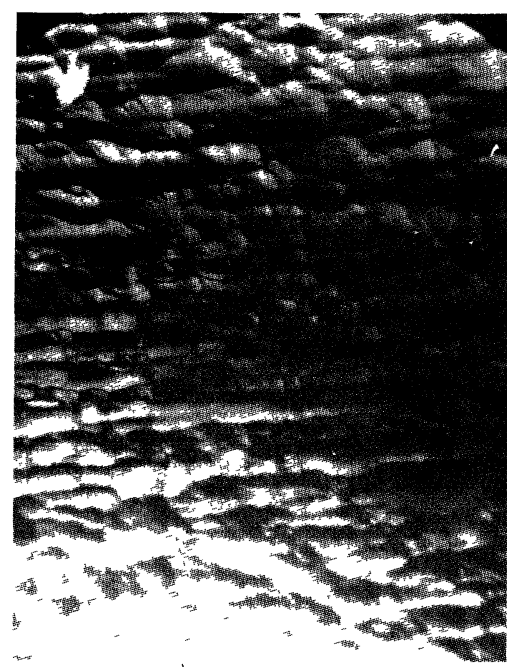

$\mathrm{x} \mathrm{Sb}=10 \%$

$100 \mu \mathrm{m}$

FIG. 1. - Influence of the composition $x$ of the ternary $\mathrm{GaAs}_{1-x} \mathrm{Sb}_{x}$ layer on its surface aspect in the case of one single layer directly grown on the substrate. 


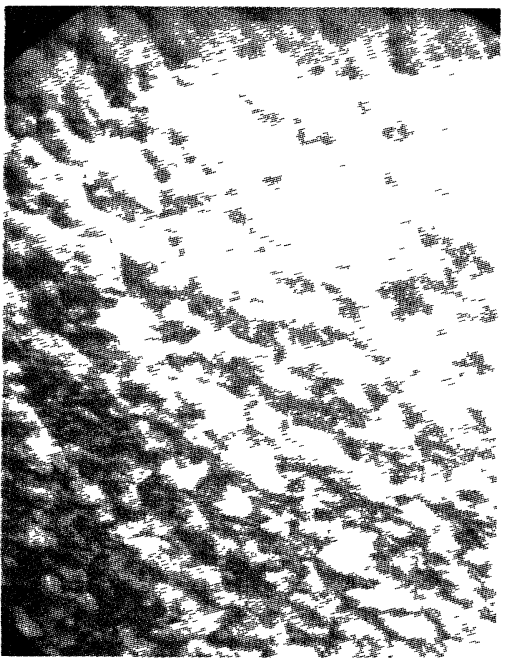

$$
\begin{aligned}
& x_{1}=6 \\
& x_{2}=9 \\
& x_{3}=11 \\
& x_{4}=12
\end{aligned}
$$

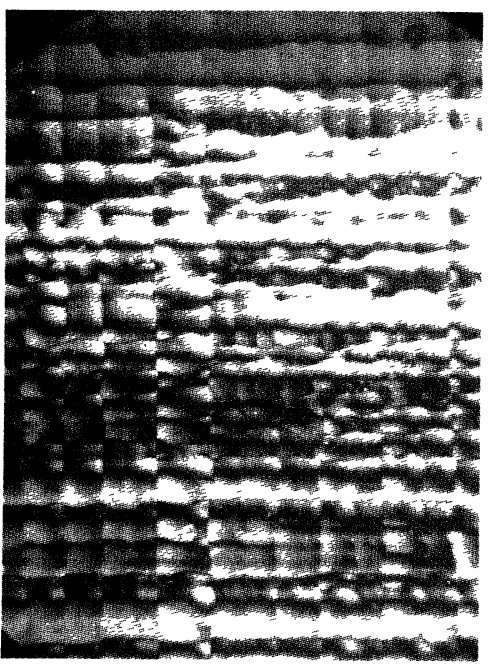

$$
\begin{aligned}
& x_{1}=3 \\
& x_{2}=6 \\
& x_{3}=9 \\
& x_{4}=12
\end{aligned}
$$

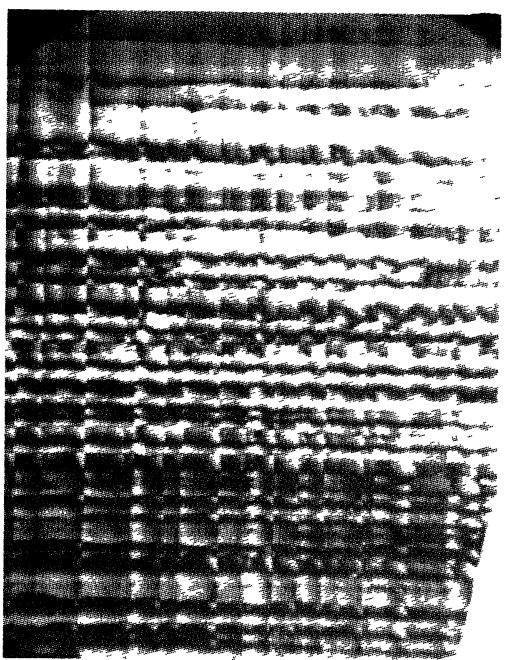

$$
\begin{aligned}
& x_{1}=1 \\
& x_{2}=3 \\
& x_{3}=6 \\
& x_{4}=12
\end{aligned}
$$

$100 \mu \mathrm{m}$

FIG. 2. - Influence of the form of the compositional steps in the buffer layer on the surface of the uppermost layer, their number being kept equal to 4 .

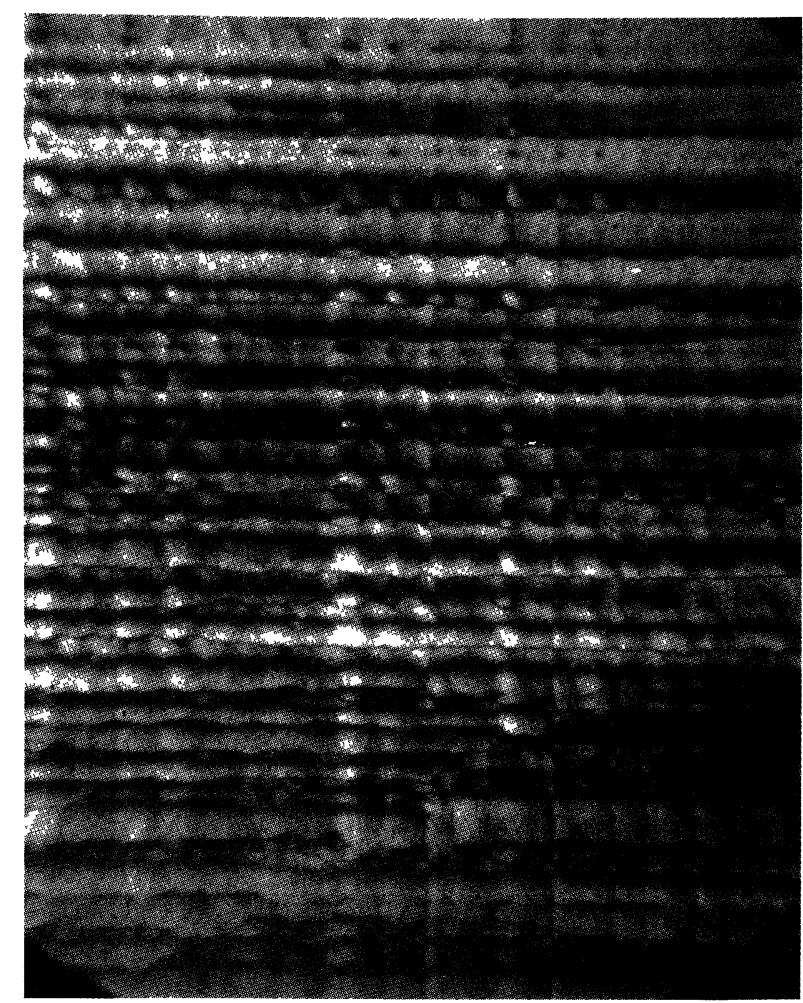

a) 4 layers

$100 \mu \mathrm{m}$

$$
\begin{aligned}
& x_{1}=1 \\
& x_{2}=3 \\
& x_{3}=6
\end{aligned}
$$

FIG. 3. - Influence of the number of compositional steps in the buffer layer on the surface of the upper layer (the configuration of the buffer layer is that with increasing compositional steps).
b) 6 layers
$x_{1}=0.8$
$x_{4}=5.5$
$x_{2}=2$
$x_{5}=8$
$x_{3}=3,5$
$x_{6}=12$ 
each interface of the buffer layer, from the substrate to the upper layer.

Similarly the number of these intermediate layers has a strong influence on the crystallographic quality of the upper layer. Figure 3 shows the surface of two uppermost layers with $12 \% \mathrm{Sb}$, grown on buffer layers having both the configuration of progressive steps but with four layers in case $a$ ) and six layers in case $b$ ). The surface quality is far better for the sample having 6 grading steps. Indeed in this case the relative variation of composition $\Delta x / x$ is the lowest. However it seems difficult to still increase the number of intermediate layers because of the limitations of the epitaxial technique (number of compartments of the crucible), particularly for GaAsSb layers with an antimony content greater than $12 \%$. For example the growth of a GaAsSb upper layer with $20 \% \mathrm{Sb}$ requires the use of at least 9 different solutions. And due to these experimental conditions ternary layers with an antimony content greater than $20 \%$ are difficult to obtain with a good crystallographic quality.

2.3 DOPING AND REALIZATION OF DOUBLE HETEROSTRUCTURE. - N-type doping is achieved by incorporating Te or $\mathrm{Sn}$ in the growth solution. As in $\mathrm{GaAs}$, tellurium is an efficient doping impurity giving way to high doping levels. On the contrary tin leads to lower and so that more easily checked dopant concentrations. Germanium is used as p-type impurity.

To perform double heterostructures with a $\mathrm{GaAs}_{1-x} \mathrm{Sb}_{x}$ active layer, quaternary

$$
\mathrm{Ga}_{1-y} \mathrm{Al}_{y} \mathrm{As}_{1-x} \mathrm{Sb}_{x}
$$

layers (with the same Sb content) are added on both sides of this active layer to achieve electronic and optical confinement. Indeed the substitution of aluminium atoms on gallium sites produces the same effect as in the binary compound GaAs : the forbidden bandgap increases but the lattice constant does not vary. Moreover crystallographic quality does not suffer any alteration due to aluminium incorporation. The cross section of such a GaAsSb/GaAlAsSb double heterostructure is shown in figure 4 ; the flatness of the different interfaces is noticeable. The whole buffer layer and the first GaAlAsSb layer (injection layer) are $n$-type, doped with tin; the active layer and the confined layer are p-type doped with germanium (the majority carrier concentration in the active layer is around $2 \times 10^{18} \mathrm{~cm}^{-3}$ ). To prepare the device, proton bombardment and $\mathrm{Au}(\mathrm{Be} 1 \%$ ) evaporation are carried out on the upper layer to respectively achieve localization of the emitting area and metallisation. The GaAs substrate is then lapped to reduce the slice thickness to $150 \mu \mathrm{m}$. Tin evaporation is performed on the lapped face for $\mathrm{n}^{+}$type ohmic contacting.

3. Results : characterization. - Ternary and quaternary layers as well as double heterostructure lightemitting diodes are characterized using S.E.M., cathodoluminescence apparatus, electrical and optical measurement technics.

3.1 S.E.M. ANALYSIS. - By the use of the cathodoluminescence mode of the S.E.M. crystallographic defects, particularly dislocations, can be revealed. Examination by this way of a cross section of the buffer layer shows the extent of the defects due to the sudden compositional steps : these defects, generated at the interfaces spread over a distance of around $2 \mu \mathrm{m}$. So the step layers must be at least $4 \mu \mathrm{m}$ in thickness. The same means used on the surface of the upper layer gives a rough value of the dislocation density in this layer. Figure 5 shows that this defect density increases when the antimony content in the upper layer increases; thus, for a GaAsSb upper layer with $12 \% \mathrm{Sb}$, the dislocation density is around $10^{5} \mathrm{~cm}^{-2}$.

Minority carrier diffusion lengths in the ternary compound can be estimated by another mode of the S.E.M. : the electron beam induced current mode. These electrical measurements are carried out on GaAsisb p-n homojunctions because the E.B.I.C. signal would be disturbed by the double heterostructure. By this method, in p-type GaAsSb material doped to $5 \times 10^{18} \mathrm{~cm}^{-3}$ with germanium electron diffusion length is found to be around 2 to $3 \mu \mathrm{m}$.
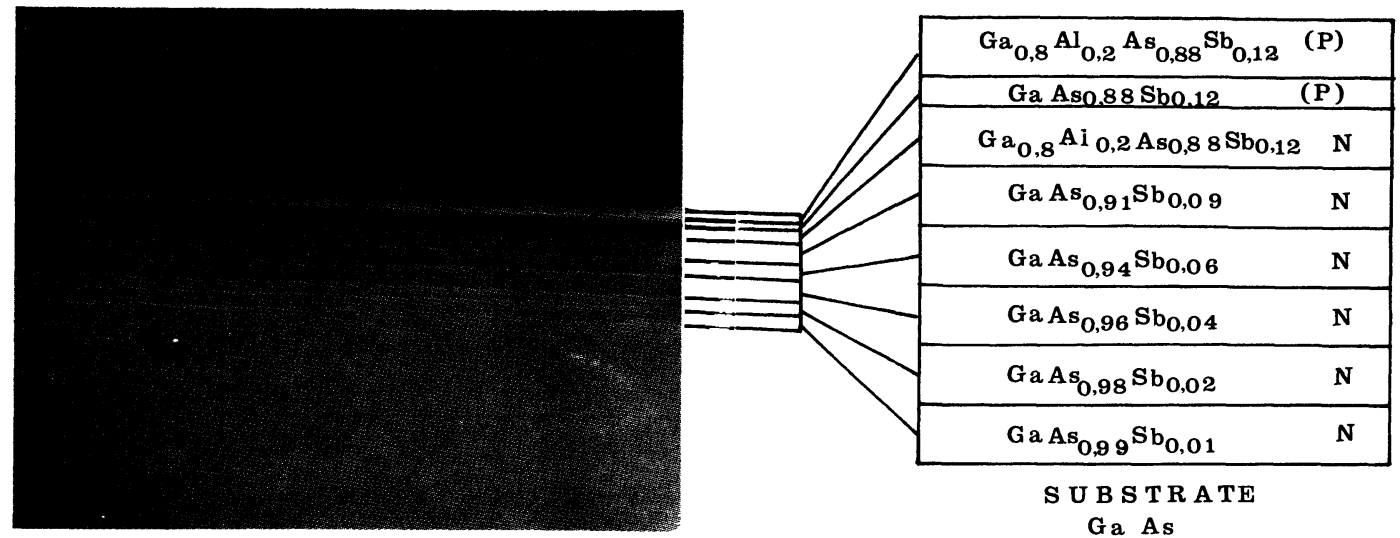

FIG. 4. - Double heterostructure cross-section : the antimony content of the active layer is $12 \% ; 5$ layers are required for lattice matching and 2 quaternary layers for the confinement. 


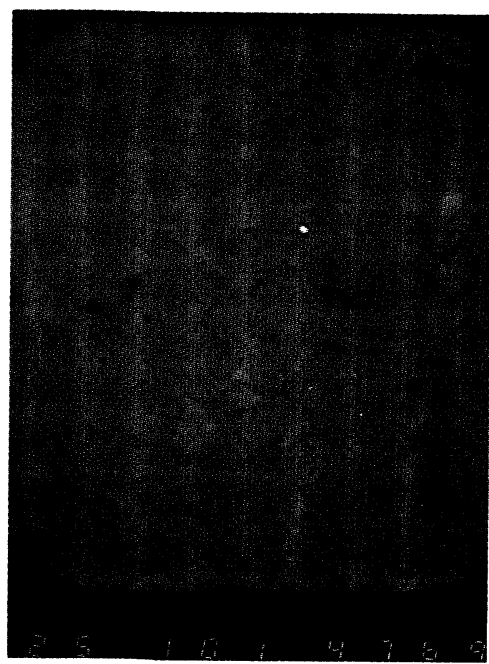

$\longmapsto \quad x \mathrm{Sb}=2 \%$

$100 \mu \mathrm{m}$

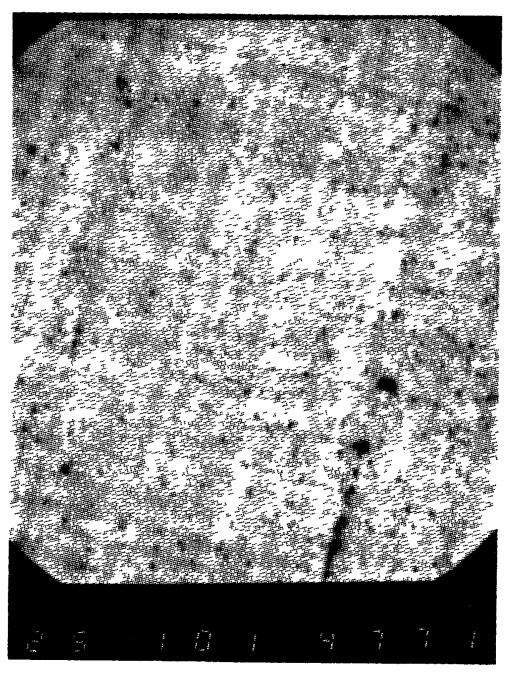

$\mathrm{x} \mathrm{Sb}=8 \%$

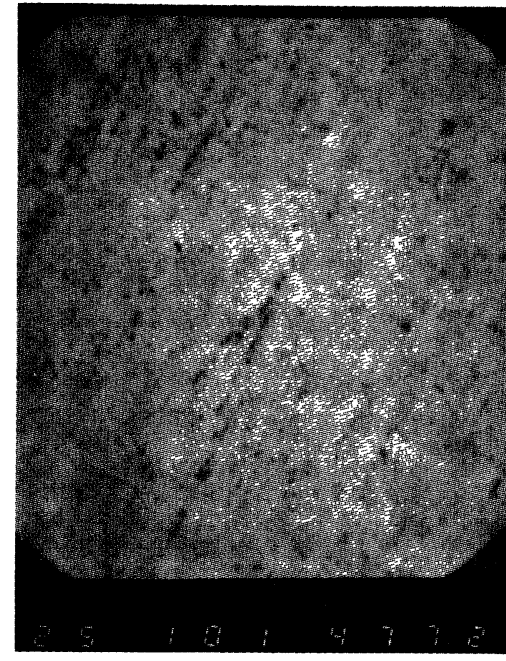

$\mathrm{x} \mathrm{Sb}=12 \%$

FIG. 5. - Influence of the antimony content in the upper layer observed in cathodoluminescence-mode SEM images of the surface. (For a $\mathrm{Sb}$ content greater than $4 \%$ the step-grading is realized with optimal conditions.)

3.2 CathodoluminesCence ANAlYSis. - Cathodoluminescence is an efficient way to characterize ternary compounds since it allows first to know exactly the composition of the solid solution and also to have an estimation of the material quality by a comparison of the respective intensities of cathodoluminescence spectra.

$\mathrm{GaAsSb}$ is a direct band-gap compound over the whole range of $\mathrm{Sb}$ compositions. So its cathodoluminescence spectra have a dissymetrical shape with a tail for high energy photons, which is typical for direct radiative transitions between the valence band and the conduction band.

Firstly the influence of temperature is viewed. In regard to this parameter, GaAsSb has the same behaviour as the binary compound GaAs with a linear variation for the band-gap between 90 and $300 \mathrm{~K}$ $\left(\Delta \varepsilon_{\mathrm{g}} \simeq 80 \mathrm{meV}\right.$ between 90 and $\left.300 \mathrm{~K}\right)$ and with the same evolution for the cathodoluminescence intensity $\left(I_{\mathrm{CL}} \propto T^{-3 / 2}\right)$.

Then doped ternary layers are analysed. For a constant Sb content $(12 \%)$, the cathodoluminescence maximum intensity increases almost linearly with the majority carrier concentration up to an impurity concentration where too many crystallographic defects are induced so that the transition efficiency falls off. This limit doping level occurs at around $5 \times 10^{17} \mathrm{~cm}^{-3}$ for n-type material and is greater than $10^{19} \mathrm{~cm}^{-3}$ for p-type material. In the same time, cathodoluminescence spectrum gets wider withincreasing impurity concentration, evidence of the filling of the states in the conduction band. A small shift of the CL spectrum towards higher energies can be also seen when the doping level increases; it may be due to a slight variation of the $\mathrm{Sb}$ composition of the solid solution or to the Burstein shift for n-type doping.
Then attention is focused on the influence of the antimony content of the ternary compound on its cathodoluminescence maximum intensity. In that aim,

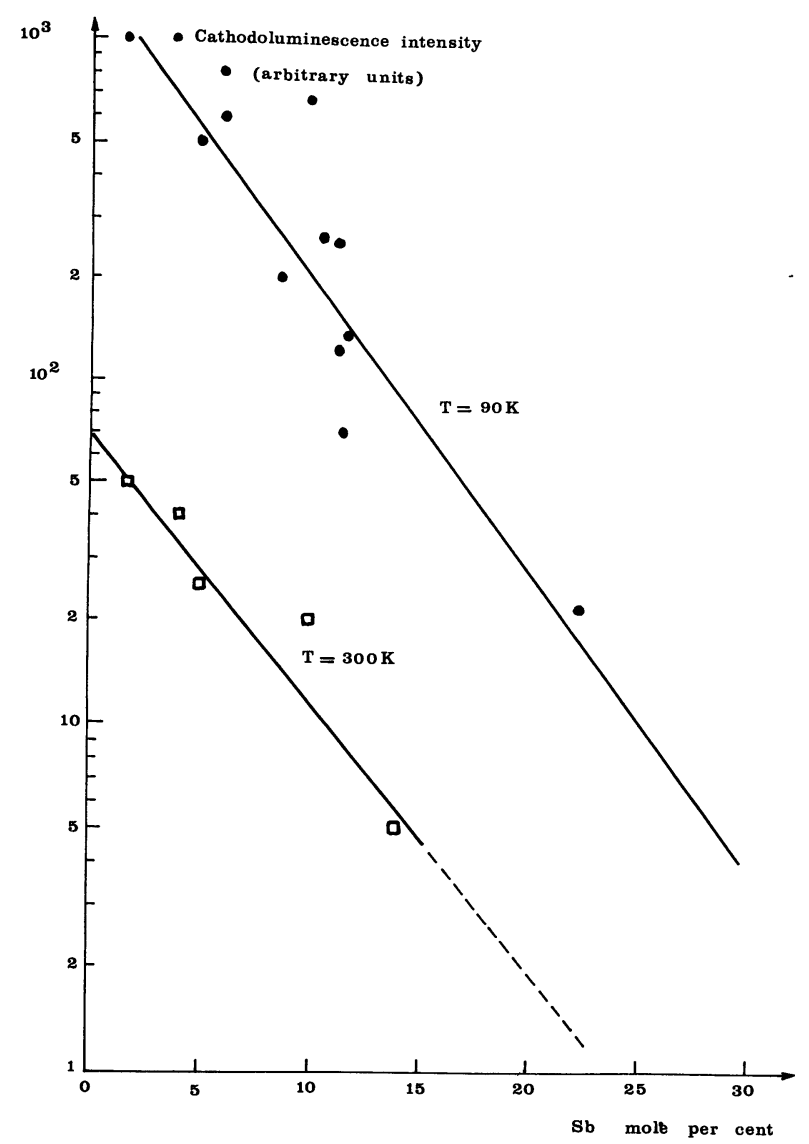

FIG. 6. - Influence of the Sb content in the ternary solid-solution on its cathodoluminescence efficiency. These layers are undoped with a background doping level around $5 \times 10^{16} \mathrm{~cm}^{-3}$; lattice matching is carried out with the optimal configuration step-grading. 
a series of samples having different $\mathrm{Sb}$ compositions is prepared without impurity doping; the background doping level is about $5 \times 10^{16} \mathrm{~cm}^{-3}$ (n-type). The Sb compositions range concerned spreads between 0 and $25 \%$; beyond this value, the crystallographic quality is too much disturbed, as previously seen. The values of the CL maximum intensity measured at 90 and $300 \mathrm{~K}$ for all these different samples are put down on figure 6. This points out a diminution of the CL intensity when the $\mathrm{Sb}$ content in the ternary compound is increased; the decrease of CL efficiency is related with the increase of the density of dislocations which comes from the lattice mismatch getting greater when antimony incorporation in the ternary solid solution increases. This decrease of efficiency is perceptible as soon as the $\mathrm{Sb}$ composition equals $5 \%$ and is the same for both temperatures : 90 and $300 \mathrm{~K}$.

3. 3 DOUBLE HETEROSTRUCTURES PERFORMANCES. Finally double heterojunction light emitting diodes with a GaAsSb active layer having a Sb composition between 0 and $20 \%$ are performed to measure their device characteristics, i.e. electroluminescence spectra are plotted for all the different samples; the spectral width nearly keeps the same value : about $50 \mathrm{meV}$ at half-height for the studied range of Sb compositions. The maximum EL efficiency is correlated with the corresponding peak emission wavelength on figure 7 . This curve is approximately a straight line with negative slope. In fact, as the emission wavelength is in direct ratio to the antimony content of the ternary compound, this points out a diminution of the EL efficiency when the $\mathrm{Sb}$ composition is increased; which is to be related to the analogous behaviour of the cathodoluminescence efficiency and can be explained by the increasing amount of crystalline defects in the active layer. Thus the EL power of a device emitting at $1.2 \mu \mathrm{m}(25 \%)$ is about 10 times lower than that of a device emitting at $1.05 \mu \mathrm{m}(12 \% \mathrm{Sb})$ which has already lost an order of magnitude in light emitting power with regard to a device emitting at $0.9 \mu \mathrm{m}(3 \% \mathrm{Sb})$. Besides the $\mathrm{GaAsSb} / \mathrm{GaAlAsSb}$ double heterostructure gives quite satisfactory results over the range of composition $0-25 \%$, as far as the response time $t_{\mathrm{m}}$ of LED's is concerned. Indeed the measurement of $t_{\mathrm{m}}$ carried out on these devices always leads to values less than $10 \mathrm{~ns}$. This value is limited not by the minority carrier lifetime which is far less, but by the junction capacitance. Therefore these response times are rightly comparable with those of light sources made of GaAlAs in their own field.

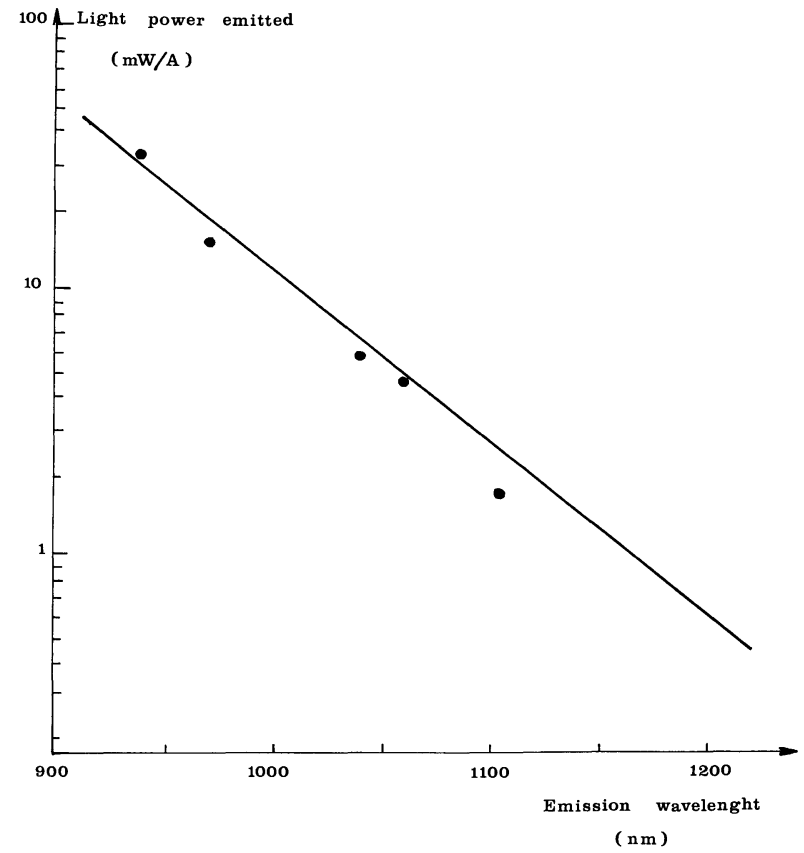

FIG. 7. - Correlation between the peak electroluminescence efficiency and the peak emission wavelength for double heterojunction LED's with a $\mathrm{GaAs}_{1-x} \mathrm{Sb}_{x}$ active layer, $0 \leqslant x \leqslant 0.25$. Increasing compositional steps have been used for the graded layer.

4. Discussion. - In summary the ternary compound $\mathrm{GaAs}_{1-x} \mathrm{Sb}_{x}$ looks attractive for light sources in optical systems working around $1 \mu \mathrm{m}$

It can easily be grown by LPE on a GaAs substrate, provided the lattice matching is carried out by the step-grading technic. Due to the degradation of the crystalline quality which occurs when the antimony content in the ternary solid solution increases beyond $20 \% \mathrm{Sb}$, the efficiency of the DHJ devices falls off quite sharply to reach a too low value when the emission wavelength is around $1.2 \mu \mathrm{m}$. But their performances (electroluminescence efficiency and rise time) at wavelengths around $1 \mu \mathrm{m}$ can favourably be compared with those of GaAlAs double heterostructures. In conclusion the application field of devices made of GaAsSb seems limited to the range 0.9 to $1.1 \mu \mathrm{m}$ but $\mathrm{GaAsSb}$ is quite well adapted to this reduced range of wavelengths.

When looking at emission wavelengths close to $1.2 \mu \mathrm{m}$, where the dispersion in silica fibers is even lower, one has to consider another material such as the quaternary system GaInAsP, on which running studies are focused.

\section{References}

[1] Antypas, G. A., Moon, R. L., J.E.S. 121 (1974) 416.

[2] Nahory, R. E., Pollack, M. A., Bebbe, E. D., De Winter, J. C., Appl. Phys. Lett. 28 (1976) 19.
[3] Nahory, R. E., Pollack, M. A., De Winter, J. C., Williams, K. M., J. Appl. Phys. 48 (1977) 1607.

[4] Olsen, G. H., Abrahams, M. S., Buiocchi, C. J., ZamerowSKI, T. J., J. Appl. Phys. 46 (1975) 1643. 